\title{
Percepção de enfermeiros sobre a morte e o morrer: influência do ensino acadêmico
}

\author{
Márcia Gabriela Rodrigues de Lima* Elisabeta Albertina Nietsche** \\ Larice Gonçalves Terra*** Roberta Corrêa Stangherlin ${ }^{\star \star *}$ Talita \\ Daiana Belmont*** Cristiane Apio Motta**** Cátia Regina Loureiro

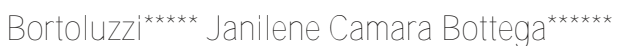

Resumo: Objetivo - Identificar como enfermeiros percebem o morrer e a morte, e se essa temática foi trabalhada durante a academia. Metodologia - Estudo de campo, descritivo-exploratório, com abordagem qualitativa, realizado em um Hospital Escola no Rio Grande do Sul, em 2010. Utilizou-se como instrumento de coleta de dados a entrevista semiestruturada e os dados foram analisados com a técnica de Análise de Conteúdo. Resultados - Os enfermeiros percebem o processo de morrer e morte como processo vital que fomenta sentimentos de impotência e medo, tanto no período acadêmico quanto no exercício profissional. Já que, receberam pouca preparação sobre essa temática. Conclusão - Deve haver maior incremento em disciplinas curriculares, para auxiliar no cuidado ao paciente em processo de morrer e morte.

Descritores: Educação, Morte, Enfermagem.

Perception of nurses about the dying and death: influence of the academic

training

Abstract: Objective - To identify how nurses understand the dying and death and if this theme was worked during the academy. Methodology - Exploratory descriptive research, with qualitative approach, in a Teaching Hospital of the Rio Grande of South, in 2010. How instrument of data collection was used the semi-structured interview and the data were analyzed with technical of content analysis. Results The nurses perceive the dying and death a vital process that promote feelings of impotence and fear, as much in academic as in the professional practice. Since they did receive little preparation in this theme. Conclusion - Must to have higher increments relating in curriculum subjects, to assist in the care to patients in process of dying and death.

Descriptors: Education, Heath, Nursing.

*Mestre em Enfermagem pela Universidade Federal de Santa Maria (UFSM), Santa Maria, RS, Brasil.

**Doutora em Enfermagem pela Universidade Federal de Santa Catarina (UFSC), Florianópolis, SC, Brasil.

***Graduanda em Enfermagem na Universidade Federal de Santa Maria (UFSM), Santa Maria, RS, Brasil.

${ }^{* * * *}$ Graduada pela Universidade Federal de Santa Maria (UFSM), Santa Maria, RS, Brasil.

Rev. Saúde (Santa Maria), Santa Maria, v.39, n.2,

${ }^{* * * * \star}$ Especialização em andamento em Gestão em Saúde na Universidade Federal do Rio Grande do Sul (UFRGS), 171-180 Jul./Dez.2013.

Porto Alegre, RS, Brasil.

${ }^{* * * * * *}$ Graduada em enfermagem pela Universidade Federal de Santa Maria (UFSM), Santa Maria, RS, Brasil. 


\section{Introdução}

A morte, apesar de inevitável em algum momento da vida do ser humano, não é uma questão simples de ser discutida, já que, em nossa cultura ocidental, muitas vezes, é representada pelo pavor e pela não aceitação. Aceitar o fato de que nossa existência, bem como a das pessoas que amamos, tem um "prazo de validade" desconhecido pode ser uma tarefa árdua ${ }^{1}$.

Nos últimos séculos, a morte ainda tem sido vista como um tabu, geralmente como tema interditado, podendo representar sinônimo de fracasso profissional ${ }^{2}$. Assim, é neste contexto com relação à morte que se encontra 0 profissional enfermeiro, pois cotidianamente permanece em conflito, lutando pela vida e contra a morte, tomando para si a responsabilidade de salvar, curar ou aliviar, procurando preservar a vida, já que a morte, na maioria das vezes, é vista por estes profissionais como uma derrota, sendo, desta forma, incessantemente combatida ${ }^{3}$.

Desde os primórdios da civilização a morte é considerada um aspecto que fascina e, ao mesmo tempo, aterroriza a humanidade. Na pré-história, período que antecede a invenção da escrita, ela foi vivenciada como um processo natural do ciclo vital, causada por doenças do meio ambiente ou por ataque de predadores maiores e mais fortes que compunham a cadeia alimentar ${ }^{4}$.

Dentre as sociedades da antiguidade Oriental, a partir do IV milênio a.C., a civilização egípcia acreditava na vida após a morte. Por isso, se utilizavam de técnicas de mumificação na conservação dos corpos. Assim, a morte foi comparada a liberdade depois da prisão, a cura depois da doença, a luz da descoberta depois da ignorância ${ }^{4}$.

Na primeira metade da Idade Média, do século IX ao XI, a morte foi utilizada pela Igreja Católica como instrumento de manipulação dos fiéis. Já que assim era possível subornar e extorquir bens materiais do povo em troca da salvação eterna. Essa entidade religiosa havia enriquecido às custas de doações feitas pelos fiéis, que acreditavam, com isso, possíveis recompensas no céu 4 .

Em contrapartida, no final da Idade Média, do século XI até o XV, a morte teve seu momento de transição. Neste período, alguns povos europeus foram assolados pela peste, fome, cruzadas, inquisição e uma série de eventos provocadores de morte em massa ${ }^{5}$.

Consequentemente, o descontrole causado pela crise social traz à consciência do homem desta época, o temor da morte. A partir daí, conteúdos negativos começam a serem associados a ela, provocando um total estranhamento do homem diante deste evento tão perturbador 6 .

Juntamente com a Idade Moderna, século XVI a meados do século XIX, surgem novas descobertas técnico-científicas, exploração de novos continentes pela expansão comercial e marítima. Diante disso, a morte passou a ser vista como causadora de medo e vergonha. Surge, então, a representação dela enquanto fracasso e frustração, pois interrompia e interferia no projeto do homem moderno, um homem decidido a dominar e transformar 0 mundo ${ }^{7}$.

Já na Idade Contemporânea, século XX ao atual, em que predomina a Era do

Saúde (Santa Maria), v.39, n.2, p.171-180, 2013. Percepção de enfermeiros sobre a morte e morrer: Capitalismo, a morte se torna mais obscura e progressivamente é incorporado como imagem negativa, cheia de ansiedade, trazendo questões não-compreendidas e não-aceitas. Por consequência, vai ocorrendo um movimento de silêncio em torno do homem que morre e do homem morto?. 
Por consequência, na área da saúde investiu-se e investe-se em inúmeras e constantes pesquisas tecnológicas que auxiliem no prolongamento da vida e, secundariamente, recuperarem o funcionamento normal da "máquina biológica": o corpo humano. Assim, com frequência, na academia são privilegiados conteúdos curriculares orientados para "salvar vidas" em detrimento da discussão sobre o morrer e a morte ${ }^{8}$.

Desta forma, durante a graduação, em aulas práticas nas unidades do hospital, observou-se que a morte de pacientes, geralmente, despertava tristeza e inquietação em alguns membros da equipe de enfermagem. A partir disso, emergiu a questão norteadora desse estudo: Como os enfermeiros se deparam com o morrer em sua tarefa do cuidar? Como foi o processo de ensino e aprendizagem sobre a morte durante o seu período de formação acadêmica?

Sob outro enfoque, fomentar discussão acerca do morrer e da morte, agregado a contribuições de outros autores, possibilita reforçar a necessidade de se desconstruir, (re) construir novos pilares para os conteúdos curriculares. Já que o instrumento de trabalho dos profissionais da saúde gira em torno das fases do ciclo vital de outros seres humanos que, inevitavelmente, também compreende a fase da morte.

A legislação sobre o ensino de enfermagem desde a criação da Escola de Enfermagem Anna Nery, que compreende os currículos de 1923, 1949, 1962 e 1972, revela uma formação de enfermeiros centrada no pólo indivíduo/ doença/cura e na assistência hospitalar, seguindo o mercado de trabalho específico de cada época.

Frente a essa problemática elaborou-se esse estudo com o objetivo de identificar como os enfermeiros percebem o morrer e a morte e se essa temática foi trabalhada durante a academia. Possibilitando assim, saber quais os reflexos desse ensino na sua atuação profissional cotidiana.

\section{Metodologia}

Trata-se de uma pesquisa exploratório- descritiva, com abordagem qualitativa, realizada em 2010. Os critérios de inclusão dos enfermeiros foram: ser enfermeiro atuante na Unidade de Clínica Médica de um Hospital Escola do interior do Rio Grande do Sul, estar de acordo em participar do estudo e assinar o Termo de Consentimento Livre e Esclarecido. Os critérios de exclusão foram: enfermeiros que estivessem em férias, licença ou afastamento de qualquer natureza no período de coleta de dados. A escolha desta Unidade foi por caracterizar-se de uma clientela acometida por enfermidades crônico-degenerativas, em sua maioria, de grave quadro clínico. Em decorrência disso, os pacientes permaneciam por longo tempo de internação, onde, muitas vezes, apresentam-se em fase terminal de vida e evoluíam rapidamente ao óbito.

Iniciou-se a coleta de dados após a aprovação do Comitê de Ética da universidade onde estava vinculada a pesquisa, com o $n^{0}$ do processo 23081.015582/2009-18. A coleta de dados foi realizada por meio de uma entrevista semi-estruturada. Sendo que, com a prévia autorização dos entrevistados, as falas foram armazenadas em gravador digital do tipo mp3 player e transcritas em seguida, visando à manutenção da integralidade das falas e à privacidade dos sujeitos.

0 instrumento de coleta de dados constitui-se de um roteiro de entrevista semiestruturada que continha os seguintes questionamentos: dados de identificação (Sexo, Tempo

Rev. Saúde (Santa Maria), Santa Maria, v.39, n.2, p.171-180 Jul./Dez.2013. Lima, M. G. R., et al. ISSN $2236-5843$ 
de serviço total e Tempo de formação) e questionamentos referentes ao processo de morrer e morte (O que você entende por "morte"? Quais sentimentos são desencadeados no momento da morte do paciente? Você teve alguma disciplina durante a academia que tratasse exclusivamente de paciente terminal e morte? Se teve essa disciplina causou alguma mudança na sua percepção anterior sobre a morte? Se não teve sentiu falta desse aprendizado em alguma situação que se viu diante da morte de algum paciente?).

Cabe ressaltar que todos os enfermeiros (sete) aceitaram participar da pesquisa e as entrevistas foram efetivadas por meio de agendamentos feitos pessoalmente, para não prejudicar o fluxo das atividades laborais na Unidade. As entrevistas foram realizadas nos turnos da manhã, tarde e noite, em local distinto tal como na sala de reuniões da Unidade. Momentos antes da realização das entrevistas foram explicitados, novamente, mas de forma breve, os objetivos da pesquisa, bem como o porquê do gravador de voz. Assim sendo, este fato não gerou problemas quanto à coleta dos dados durante a entrevista.

Ao mesmo tempo, ao aceitarem se integrar à pesquisa, os sujeitos tiveram, de forma clara e objetiva, os seus principais direitos enumerados. São eles: anonimato; privacidade; sigilo; livre escolha (autonomia) em participar ou não do estudo; direito de retirar o seu consentimento em qualquer período sem sofrer represália ou quaisquer prejuízos pessoais ou institucionais à sua pessoa e direito de receber respostas a todas as dúvidas relacionadas à pesquisa que, porventura, viessem a aparecer. O Termo de Consentimento Livre e Esclarecido especificou todas as questões, sendo que ele foi lido e assinado pelos pesquisadores e sujeitos pesquisados, em duas vias: uma permaneceu com em posse dos pesquisadores e a outra, dos sujeitos participantes conforme resolução 196/969.

Além disso, respeitando os direitos de privacidade nessa pesquisa foram adotados codinomes egípcios (ANÚBIS, ÍSIS, OSÍRIS, HATOR, NEFERTITE, CLEÓPATRA E TUTANKAMON) para identificar os enfermeiros, mantendo assim o anonimato dos mesmos e homenagear um dos primeiros povos que se utilizaram de técnicas de mumificação para driblar a morte ${ }^{10}$

O processo de análise de dados, juntamente com a discussão e a interpretação destes, foi orientado pela técnica de análise de conteúdo ${ }^{11}$. Esse tipo de análise constitui-se em um conjunto de técnicas de análise das comunicações muito empírico que depende do tipo de fala a que se dedica e do tipo de interpretação que se pretende como objetivo ${ }^{11}$.

\section{Resultados e discussão}

Sobre a caracterização dos sujeitos trata-se que $86 \%(n=6)$ eram do sexo feminino e 14\% ( $n=1)$ masculino. Acerca do tempo de serviço total 29\% ( $n=2)$ tinham 15 anos, $43 \%(n=3)$ entre quatro e três anos, $14 \%(n=1)$ com dois anos e 14\% ( $n=1)$ com três meses. Referente ao tempo de formação $29 \%$ ( $n=2)$ havia concluído o curso há 15 anos, $43 \%(n=3)$ entre quatro e três anos, $14 \%(n=1)$ há dois anos e 14\% $(n=1)$ há um ano.

Após as leituras e reflexões do conteúdo produzido através das entrevistas emergiram quatro categorias, sendo elas: percepção do morrer e da morte, sentimentos desencadeados pela morte do paciente, ensino do morrer e da morte na academia e reflexos do ensino sobre o morrer e a morte no cotidiano dos enfermeiros.

Saúde (Santa Maria), v.39, n.2, p.171-180, 2013. Percepção de enfermeiros sobre a morte e morrer: influência do ensino acadêmico 


\title{
Percepcão do morrer e da morte
}

No referente à percepção da morte, a maioria dos enfermeiros a descreveu como uma simples parada cardíaca ou ausência de sinais vitais. A questão central parece estar no fato de que a morte é identificada como fracasso da instituição e do profissional, além de estar ligada a uma idéia que revela o caráter de finito, ou seja, que tudo está acabado ${ }^{12}$.

\author{
"Morte é ausência de vida" (ANÚBIS). \\ "[Morte é] falência orgânica" (OSÍRIS).
}

"[Morte] é quando a pessoa cessa os sinais vitais, para de bater o coração, para de respirar. Seria a morte do corpo" (TUTANKAMON).

Tratar a morte como uma simples parada cardíaca ou ausência de sinais vitais pode denotar-se uma estratégia de nossa "psique" para aceitá-la de uma forma mais natural. Já que esse tipo de vocabulário muito se assemelha ao utilizado pelo modelo cartesiano de Descartes, em que o corpo é considerado uma simples máquina. Onde a morte, nesse enfoque, biologista e fragmentador, representa um dano irreparável e irreversível de peças (órgãos) que não voltarão mais a funcionar².

Isso acontece porque pensar sobre a morte pode ser extremamente difícil, pois, a maioria das pessoas, conscientes ou inconscientemente, está programando a próxima etapa de suas vidas e jamais meditam sobre ela. Ainda que seja um fenômeno inevitável, sua presença afronta ${ }^{13}$. Essa dificuldade, muitas vezes é expressa pela negação desse evento enquanto finitude.

"Falar sobre morte é difícil. Logo que li o roteiro da entrevista pensei que fosse fácil" (OSÍRIS).

"[Morte] é um processo, uma passagem de uma vida para outra. Para mim a vida é um momento e o processo depois da morte é outro. Não significa ao pé da palavra "acabou", "nunca mais". Para mim é uma passagem para outra vida" (CLEÓPATRA).

Diante disso, o profissional da saúde, com frequência, atribui à morte inúmeras significações dependendo do contexto e da vulnerabilidade dos indivíduos. Sendo assim, fragmentar essa percepção pode constituir-se em uma barreira eficiente ao proteger-se do sofrimento ${ }^{13}$.

"A morte é assim. Depende de se eu falar do lado pessoal é uma coisa, se eu falar do lado profissional é outra" (HATOR).

Em contrapartida, a fim de reduzir esse sofrimento e dificuldade ao pensar/vivenciar a morte, deve-se refletir sobre esse evento a partir de uma abordagem natural ${ }^{14}$. $O$ nascimento Rev. Saúde (Santa Maria), Santa Maria, v.39, n.2, p.171-180 Jul./Dez.2013. e a morte fazem parte dos extremos do ciclo vital, pois tudo que inicia cumpre sua trajetória e 
acaba. Referente à finitude, já dizia Vinícius de Moraes no Soneto do Orfeu: Que não seja imortal, mas que seja infinito enquanto dure ${ }^{15}$.

"Morte é o processo final que faz parte da vida. É uma etapa final" (ISISS).

Contudo, a morte passou a assustar, a causar pânico, a ser negada também pelo profissional, que interpreta como negação de seu trabalho, de seu objetivo de salvar vidas. Escondeu-se o pavor, o morto e a doença incurável16. No entanto, deu-se oportunidade ao trabalhador da saúde de lidar com ela como parte de seu cotidiano, mesmo incompreendida e aceita com restrições, gerando angústias, ansiedades e mais negação que culminam em sua prática assistencial cotidiana.

\section{Sentimentos desencadeados pela morte do paciente}

O momento da morte, geralmente, desperta uma gama de sentimentos, tanto em quem morre quanto em quem assiste a esse evento. Pois, sentir-se um ser vivo desprovido de capacidades para driblar situações inevitáveis e incompreendidas pode excitar medo, angústia e, sobretudo impotência ${ }^{17}$.

"[A morte desperta] sensação de impotência" (ANÚBIS).

"[Desperta] sentimento de perda e um pouco de impotência por não poder ter participado mais" (TUTANKAMON).

"[Desperta] frustração porque você tem toda aquela empolgação assistindo o paciente e de repente ele morre" (OSÍRIS).

Todavia, é compreensível que, ao longo do tempo de internação dos pacientes, alguns profissionais estabelecem uma relação de vínculo e confiança até mesmo com familiares. Isso acontece porque há contato diário com o sofrimento desses indivíduos que se encontram frente à eminente morte de seu ente querido ${ }^{16}$. Por conseguinte, essa situação vivenciada desperta tristeza em alguns enfermeiros.

"[Desperta] tristeza pela família, pesar pelo paciente. A gente acaba se apegando pelo tempo de internação que eles ficam aqui na Unidade e acaba se vinculando a família" (HATOR).

"Infelizmente, a gente acaba vivenciando tantas situações de morte com pacientes que você fica mesmo numa situação de ressentimento em relação ao familiar e fica aquele sentimento de pena em relação à morte do paciente" (NEFERTITE).

Entretanto, muitos profissionais adotam uma postura rígida frente à perda do paciente,

Saúde (Santa Maria), v.39, n.2, p.171-180, 2013. Percepçäo de enfermeiros sobre a morte e morrer: influência do ensino acadêmico ISSN 2236-58347 como se isso the conferisse proteção contra o inevitável. Mediante tal postura, isenta de sentimentalismo ao envolver-se apenas profissionalmente, após o passar dos anos de prática, parece ser tendência lógica ao adaptar-se à situação de morte como rotina ${ }^{17}$. 
"No início do meu trabalho eu me colocava muito no lugar da família, sofria muito, ficava bem "agoniada". Depois com o tempo a gente acaba se tornando, não é que fique fria, mas às vezes, isso parece que faz parte do trabalho" (CLEÓPATRA).

"Quando a gente é acadêmica não está preparada para isso, então, às vezes, a gente se desespera um pouco, mas aos poucos vai aprendendo a lidar com isso (ISÍS).

Sob outro aspecto, entre os agravantes da percepção do sofrimento sobre a morte, destacam-se os aspectos relativos à faixa etária. Pois, quanto mais jovens forem os pacientes que morrem, mais traumatizante se torna esse acontecimento aos profissionais, muito mais ainda, em se tratando de crianças ${ }^{17}$. Em decorrência, a maior angústia acontece porque a morte na infância interrompe 0 ciclo natural da vida e não permite desfrutar dos sonhos e esperanças futuras.

"[A experiência que marcou minha vida] foi com uma criança de dois ou três anos. Marcou o desespero dos pais" (ANÚBIS).

"[Marcou] um paciente jovem que precisava de um respirador para continuar vivendo" (NEFERTITE).

Em síntese, o evento da morte por si só fomenta emoções nos indivíduos por representar finitude, acabamento da vida, terminalidade, encerramento do ciclo. Todavia, quando está aliada a outros fatores como vínculo, convivência e cumplicidade entre a tríade profissional-paciente-familiares, os sentimentos de tristeza, impotência, ansiedade e medo potencializam-se tornando a dor da perda, algo ainda maior.

\section{Ensino do morrer e da morte na academia}

$O$ acadêmico de enfermagem ainda está sendo preparado com maior ênfase para lidar com a vida no tangencial a aspectos técnicos e práticos da função profissional ${ }^{18}$. Há pouca ênfase em questões emocionais e na instrumentalização para o duelo constante entre a vida e a morte.

"Não tive nada a respeito [na academia]" (ANÚBIS).

"Alguma coisa foi falada [na academia], mas não alguma disciplina que falasse assim exclusivamente sobre a morte" (ISIS).

A morte parece ser pouco abordada durante as aulas práticas com os acadêmicos, mas apenas superficialmente dentro da sala aula, distante da verdadeira realidade que espreita no cotidiano assistencial. Trata-se enfaticamente, em conteúdos curriculares, sobre as técnicas e procedimentos que devem ser dominadas com precisão e agilidade, em detrimento da Rev. Saúde (Santa Maria), Santa Maria, v.39, n.2, p.171-180 Jul./Dez.2013. subjetividade suscitada em eventos como o da morte. 
"Tive (essa matéria sobre morte) no $2^{\circ}$ ou $3^{\circ}$ semestre em Psicologia da Saúde" (OSÍRIS).

"[Tive] dentro da Psicologia. A gente lia aquele livro da Kübler-Ross e depois dialogava /conversava" (TUTANKAMON).

Embora tenha ocorrido aumento no número de publicações sobre o tema, a morte é um desafio para o enfermeiro, pois nem todas as escolas de Enfermagem dedicam-se atentamente a oferecer ao acadêmico, formação mais acurada relativa ao morrer. Não se sabe como e quanto essa deficiência desgasta 0 aluno, 0 docente e o próprio paciente ${ }^{19}$. Por consequência, é relevante formar educadores habilitados para traçar linhas mestras de reflexões, pesquisas e práticas profissionais sobre o tema morte/morrer e na formação de profissionais mais preparados para o enfrentamento desta situação no desenvolvimento de atividades laborais.

\section{$\underline{\text { Reflexos do ensino sobre o morrer e a morte no cotidiano dos enfermeiros }}$}

Educar para a vida implica entender a morte como uma manifestação vital, como algo decorrente do viver, por mais contraditório que tal afirmação possa parecer ${ }^{19}$. Referente a isso os enfermeiros destacaram consideráveis necessidades no ensino e aprendizado acerca da Tanatologia.

"Com certeza senti falta desse aprendizado" (ANÚBIS).

"Se eu tivesse tido essa disciplina teria facilitado" (NEFERTITE).

Por conseguinte, a deficiência no ensino sobre o morrer e a morte manifesta-se com maior ênfase quando 0 acadêmico depara-se com situações de óbito de pacientes no ambiente hospitalar e, a partir de então,vivenciar esse evento.

"[O estudo da morte] foi uma parte bem falha na academia. Porque quando a gente ta na faculdade somos super jovens e a maioria não teve experiência nenhuma de morte na família. Enfim, você entra no hospital, um ambiente bem conturbado e começa a se deparar com a morte, então você não sabe como lidar, com as famílias principalmente" (HATOR).

Diante disso, estudar a morte é algo que pode auxiliar no trabalho com sua constante presença, surgindo, daí, a necessidade do profissional tornar-se familiarizado com 0 assunto desde a graduação, com vistas a um preparo pessoal e profissional ${ }^{12}$. Assim, potencializa-se assistir aos pacientes dentro de uma esfera integral e humanizada, com vistas ao um cuidado eficiente e efetivo em todas as fases do ciclo da vida.

Saúde (Santa Maria), v.39, n.2, p.171-180, 2013. Percepção de enfermeiros sobre a morte e morrer: influência do ensino acadêmico 178 ISSN 2236-58347
"Seria importante ter alguma disciplina sobre isso, alguma coisa que tratasse mais daquelas cinco fases da morte: aceitação, negação, barganha" (ISÍS).

"A gente tem um melhor entendimento da morte na prática do que na teoria. Você vivenciar aquele processo é diferente" (CLEÓPATRA). 
Nas universidades e hospitais, urge o fomento de disciplinas, grupos de estudos, seminários, centros de discussões sobre a morte e o morrer, como estratégia ao preparo dos profissionais ${ }^{19}$. Visto que, a deficiência sobre 0 ensino nessa temática refletiu consideravelmente na atuação profissional dos enfermeiros participantes. As entrevistas sinalizam que os enfermeiros sentiram falta da abordagem sobre morrer/morte durante a academia, o que poderia minimizar as dificuldades de enfrentamento desta situação na pratica assistencial.

\section{Conclusão}

Os enfermeiros sinalizam que a morte/morrer significa algo que finaliza a existência humana, e por consequência, a ocorrência desse evento desperta nesses sujeitos sentimentos de impotência, tristeza e ansiedade, tanto ao nível de experiência profissional como ao nível pessoal, que aos poucos vão sendo amenizados pela experiência adquirida no tempo de serviço.

Outra questão muito importante levantada por este estudo é que, ao longo da academia, a maioria dos enfermeiros não teve nenhuma disciplina que contemplasse o tema morte com a ênfase necessária, diante de sua grande complexidade e magnitude. Essa deficiência refletiu na dificuldade que os mesmos possuíram ao se deparar com situações de morte de pacientes durante 0 exercício profissional.

Acredita-se que a abordagem do processo de morrer e morte não deve limitar-se à discussão apenas ao nível de conteúdos curriculares que agregam cursos de graduação em saúde, pois a magnitude de tal assunto abrange uma esfera ampla que tange princípios e valores adquiridos desde a infância.

Refletir sobre a finitude é uma prática que pode gerar imenso sofrimento e tristeza devido ao mistério envolto a esse evento. A partir disso, acredita-se que viver intensamente cada fase da vida, quando possível, tomando consciência da morte em sua mais profunda essência, pode auxiliar na compreensão da mesma, não como inimiga a ser combatida, mas como a página de encerramento de um livro que narra a trajetória de uma formidável "estrela" que se apaga: a existência humana.

\section{Referências Bibliográficas}

1. Silva KS, Ribeiro RG, Kruse MHL. Discursos de enfermeiras sobre morte e morrer: vontade ou verdade? Rev Bras Enferm. 2009;62(3):451-6.

2. Sousa DM, Soares EO, Costa KMS, Pacífico ALC, Parente ACM. A vivência da enfermeira no processo de morte e morrer dos pacientes oncológicos. Texto \& Contexto Enferm. 2009;18(1):41-7.

3. Machado WCA, Leite JL. Eros e Thanatos: a morte sob a óptica da enfermagem. São Caetano do Sul (SP): Yendis; 2006.

4. Figueiredo MTA, organizador. Coletânea de textos cuidados paliativos e tanatologia. São Paulo: s.ed., 2009.

Rev. Saúde (Santa Maria), Santa Maria, v.39, n.2, p.171-180 Jul./Dez.2013.

5. Pessini L. Cuidados paliativos: alguns aspectos conceituais, biográficos e éticos. Rev Prática Hospitalar. Lima, M. G. R., et al. 2005;41(7):107-12. 
6. Santos JL, Bueno SMV. Educação para a morte a docentes e discentes de enfermagem: revisão documental da literatura científica. Rev Esc Enferm USP. 2011;45(1):272-6.

7. Bernieri J, Hirdes A. O Preparo dos acadêmicos de Enfermagem brasileiros para vivenciarem o processo morte-morrer. Texto \& Contexto Enferm. 2007;6(1):89-96.

10. Ministério da Saúde (BR). Conselho Nacional de Saúde. Resolução nº 196/96, de 10 de outurbo de 1996. Aprova as diretrizes e normas regulamentadoras de pesquisas envolvendo seres humanos. Brasília (DF): Ministério da Saúde; 1996.

11. Ordoñez M, Quevedo J. História geral. São Paulo: Ed. Afiliada; 1994.

12. Bardin L. Análise de conteúdo. $7^{\text {a }}$ ed. Portugal: Editora 70; 2009.

13. Costa JC, Lima RAG. Luto da equipe: revelações dos profissionais de enfermagem sobre o cuidado à criança/adolescente no processo de morte e morrer. Rev Latinoam Enferm. 2005;13(2):151-7.

14. Barbosa LNF, Francisco AL, Efken KH. Morte e vida: a dialética humana. Aletheia. 2008 dez; (28):32-44.

15. França MD de, Botomé SP. É possível uma educação para morte? Psicol Estud [Internet]. 2005 [acesso em 2011 fev 11];10(3):547-8. Disponível em: http://www.scielo.br/pdf/pe/v10n3/v10n3a23.pdf

16. Rocha F. Vinícius de Moraes [Internet]. 2013 [acesso em 2013 nov 16]. Disponível em: http://www.poesiaspoemaseversos.com.br/vinicius-de-moraes-poemas-de-amor/

17. Bellato R, Araujo AP, Ferreira HF, Rodrigues PF. A abordagem do processo do morrer e da morte feita por docentes em um curso de graduação em enfermagem. Acta Paul Enferm [Internet]. 2007 [acesso em 2011 abr 30];20(3):255-63. Disponivel em: http://www.scielo.br/pdf/ape/v20n3/a03v20n3.pdf

18. Brêtas JRS, Oliveira JR, Yamaguti L. Reflexões de estudantes de enfermagem sobre morte e o morrer. Rev Esc Enferm USP. 2006;40(4):477-83.

\section{Márcia Gabriela Rodrigues de Lima}

Endereço para correspondência - Rua Afonso Potter, 2077. CEP 97200-000, Restinga Seca, RS, Brasil.

E-mail: grlmarcia@yahoo.com.br

Currículo Lattes: http://lattes.cnpq.br/5849906800115356

Enviado em 05 de abril de 2013.

Publicado em 19 de novembro de 2013.

Saúde (Santa Maria), v.39, n.2, p.171-180, 2013. 